adequate security, particularly if access to the internet is to be available. This is a large and difficult problem and not one that can be easily solved.

\section{Summary}

We have spent many years hearing about the benefits that we are about to reap from computers, but often seem to find that workloads are increased rather than decreased by the demands for ever more complex data. I certainly hope that the possibilities being offered up in this review represent more than idle dreams, and may be the first signs of computer systems that genuinely help to reduce our workload.

\section{Glossary}

- Baud - the speed of data capture. The higher the baud the quicker the device.

- Bookmarking - recording the internet address of particular site allowing rapid return to a site of interest.

- File server - central computer serving a network of different terminals.

- Processor - the engine for the computer. In increasing order of speed these include 386, 486, Pentium, or MMX processors.
- Smart cards - plastic cards, around the size of a credit card, containing detailed electronic information that can be read from and written to very readily via a computer.

Department of Paediatrics,

R I ROSS RUSSELL

Addenbrooke's Hospital,

Hills Road,

Cambridge CB2 $2 Q Q$

1 Safran C. Defining clinical 'workstation'. Int F Biomed Comput 1994;34:261-5. Suddick RP. The dental clinical workstation and the computer-based patient record. N Y State Dent f 1995;61:36-41.

3 Bellon E, Feron M, Marchal G, et al. Design for user efficiency in a dedicated ICU viewing station. Med Inform 1994;19:161-70.

4 Kiley R. Medical information on the internet. Edinburgh: Churchill Kiley R. Medical

5 Safran C, Rind DM, Sands DZ, Davis RB, Wald J, Slack WV. Development of a knowledge-based electronic patient record. MD Comput 1996;13:46$54,63$.

6 Lovell NH, Celler BG. Implementation of a clinical workstation for general practice. Medinfo 1995;8(part 1): 777

7 Kundel HL, Seshadri SB, Langlotz CP, et al. Prospective study of a PACS: information flow and clinical action in a medical intensive care unit. Radiology 1996;199:143-9.

8 Chute CG, Cesnik B, van Bemmel JH. Medical data and knowledge management by integrated medical workstations: summary and recommendations. Int $\mathcal{F}$ Biomed Comput 1994;34:175-83.

9 Lee M, Niemeyer D, Seilheimer D, Abramson S, Lin Z, Gu M. Cat 6 mo increases symptoms: online physician charting and more. Proc Annu Symp Comput Appl Med Care 1995;81-5.

10 Friesdorf W, Gross Alltag F, Konichezky S, Schwilk B, Fattroth A, Fett P. Lessons learned while building an integrated ICU workstation. Int $\mathcal{F}$ Clin Monit Comput 1994;11:89-97.

\title{
Children in residential care; what cost?
}

Young people 'looked after' in residential care by social services can be viewed as a significant problem for child health and mental health services and for education authorities. They are frequently victims, in terms of abusive backgrounds that lead many into the care system, and perpetrators, in terms of child abuse and/or committing offences such as stealing cars. These characteristics, combined with emotional and behavioural problems as well as learning difficulties, lead to great difficulties in meeting these young people's needs. Considerable input is often required from health, education, and social services resulting in inevitably high expenditure. This paper explores these needs and their associated costs.

'Health of the Nation Targets' with regard to teenage pregnancy, sexually transmitted disease, smoking, suicide, and poor diets are particularly important for those cared for in residential community homes. ${ }^{1}$ Although these health concerns are shared with this age group as a whole, prevalence is likely to be higher amoung children in residential care. Frequent moves from both outside and within the care system before a long term home is found can lead to health problems being overlooked or to poor continuity of health care.

There has been a successful drive to keep children within their own homes whenever possible and to foster those for whom this is not an option. Despite this, $19 \%$ of those being looked after nationally remain in residential care. ${ }^{2}$ Personality problems and deviant behaviour are prevalent among young people in this group. ${ }^{3}$ They require protection, supervision, support, education, consistency of environment, and stimulation. Meeting these needs successfully demands parenting of a high standard supported by personnel from health, education, and social services. ${ }^{4}$ Communication and coordination are essential, as well as agreements on how costs are shared. Failure in this respect leads to ineffective services, ${ }^{5}$ although costs may remain high.
Despite high costs, residential care is frequently associated with poor outcome with regard to employment, (50-80\% unemployment among 16-24 year olds compared with the national rate for this age group of $15.4 \%$ ); $75 \%$ have no academic qualifications (compared with an average of $6 \%$ for the same age group); homelessness (30\% of single homeless people having been in residential care); mental health, future parenting ability (one in seven young women leaving care are pregnant or already mothers); and risks of criminal conviction (38\% of young prisoners are said to have been in local authority care as a child). ${ }^{6}$ These costs have been quantified in order that the cost benefit of future strategies to reduce numbers in residential care may be evaluated.

\section{Illustrative costs}

Data are presented (table 1) from published national and local sources to indicate the expenditure that is associated with children in residential and foster care that might be incurred by local authorities and health authorities. Other expensive services need to be weighed against potential future costs, for example, unemployment $v$ employment, mental health $v$ mental illness, and the costs or lack of costs incurred by the criminal justice system. These figures are intended to be illustrative only of the comparative costs of different types of residential provision. Individual costs may be much higher, for example intensive care after overdose, orthopaedic care after serious injuries sustained while driving a stolen car, or insurance costs due to loss of vehicles or damage to property.

\section{Discussion}

Placement in residential care is approximately seven times as expensive as foster care. It is comparable with residential special school placement, although some may also attend day special school. Children receiving residential care (including specialist psychiatric care) in these settings may 
Table 1 Examples of costs of care-figures for England given where available

\begin{tabular}{|c|c|c|}
\hline Type of care & $\begin{array}{l}\text { Range in England } \\
(£ \text { per year })\end{array}$ & Average $(£)$ \\
\hline Residential $^{\star}$ & $31053-69630$ & 48 268/year \\
\hline Secure unit $\dagger$ & & 2500/week \\
\hline Foster care ${ }^{\star}$ & $3084-10211$ & $7127 /$ year \\
\hline $\begin{array}{l}\text { Secondary education } \\
\text { place }\end{array}$ & $1962-2409$ & $2232 /$ year \\
\hline Special education place ${ }^{\star}$ & 5609-14064 & $8250 /$ year \\
\hline $\begin{array}{l}\text { Residential special school } \\
\text { for children with } \\
\text { emotional and }\end{array}$ & & \\
\hline behavioural difficulties & 20-60 000/year & Not available \\
\hline $\begin{array}{l}\text { Typical private boarding } \\
\text { school } \dagger\end{array}$ & Not available & 14 000/year \\
\hline Inpatient psychiatric care $\neq$ & Not available & $\begin{array}{l}27740 / \text { consultant } \\
\text { episode }\end{array}$ \\
\hline Inpatient paediatric care $\ddagger$ & Not available & $720 /$ consultant episode \\
\hline Paediatric intensive care $\ddagger$ & Not available & $1500 /$ day \\
\hline
\end{tabular}

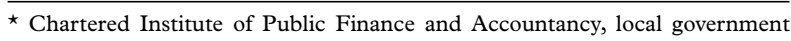
statistics for 1994-5.

† Estimated from local sources.

$\ddagger$ Local health authority charges, 1996.

indeed be very similar populations, but with different lead agencies being identified as providers. The figures quoted for cost, although high, are likely to underestimate the true total cost of care as they ignore the costs incurred by the police, education welfare officers, special education needs assessment, child health services, and insurance losses, for example as a result of vehicle theft. There are currently no means of identifying residential care costs to these individual services. High costs will be justified if they meet the complex social, educational, and mental health needs of these young people in the short and medium term and lead to improved outcomes in the long term.

The much needed trend towards adoption or placement of young people in foster care has resulted in fewer individuals requiring residential care. To meet the requirements of the 1989 Children Act, however, ${ }^{9}$ they have to be placed as near as possible to their former homes and social environment. In order to improve quality of care, a maximum of eight young people can be placed in each home. For these two reasons a critical number of residential care homes will always be required. Whatever the size, approximately 12 residential social workers are required to staff a shift system with two members of staff on site at all times. It is these staff costs that escalate the unit cost of residential care as the number of individuals requiring this service diminishes. Staff training and support are important additional costs that are vital to quality care.

Given the exceptionally high cost and relatively poor outcome of residential care, initiatives to increase the availability of foster parents are urgently needed. Studies of models of good practice and longitudinal data collection to identify positive as well as negative outcomes and trends are also required. Efforts to expand fostering must include recruitment and appropriate training of specialist foster carers, increased provision of support for foster parents, and improved monitoring of the care plans for those in foster care. Earlier intervention to support families of children in need should decrease the numbers of looked after children who require such intensive and specialised services. ${ }^{8}$ The strategies for prevention in Health of the Nation, for example in prevention of coronary artery disease rather than meeting the high costs of treatment where cure is not possible, should influence our policies for this group of children in need. ${ }^{1}$ Joint children's service plans, ${ }^{2}$ which have been mandatory for local authorities in England since March 1996, could provide an agreed joint strategy for children that are looked after, with interagency teams as providers of the specialist support that is required for young people and their carers. ${ }^{4}$

LEON POLNAY ADAM W GLASER

Department of Child Health, TONY DEWHURST

Oueen's Medical Centre,

Nottingham NG7 $2 U H$

Tony Dewhurst is employed by Nottinghamshire Social Services. None of the authors has any conflict of interest.

1 Department of Health. The health of the nation. London: HMSO, 1991.

2 Audit Commission. Seen but not heard: co-ordinating community child health and social services for children in need. London: HMSO, 1994.

3 McCann JB, James A, Wilson S, Dunn G, Prevalence of psychiatric McCann JB, James A, Wilson S, Dunn G, Prevalence of psychia
disorders in young people in the care system. BMF 1996;313:1529-30.

4 Polnay L, Glaser A, Rao V. Better health for children in resident care. Arch Dis Child 1996;75:263-5.

5 Malcolm L, Peake A, Walker C, Powerless children-powerful systems. Children in Society 1996;10:210-6.

6 Evans A. We don't choose to be homeless: report of the national enquiry into preventing youth homelessness. London: CHAR, 1996.

7 Department of Health. The Children Act 1989 (vol 4); guidance and regulations - residential care. London: HMSO, 1991.

8 Department of Health. Child protection: messages from research. London: HMSO, 1995. 